\title{
Leadership Role Identity Construction in Women's Leadership Development Programs
}

\author{
Krystal L. Brue \\ Assistant Professor \\ Department of Business \\ Cameron University \\ Shawn A. Brue \\ Licensed Marriage \& Family Therapist and Licensed Professional Counselor \\ Christian Family Counseling Center \\ Adjunct Faculty \\ Department of Marriage \& Family Therapy and Department of Psychology \\ Northcentral University \& Cameron University
}

\begin{abstract}
This article analyzes women's only leadership development training to determine how leadership roles are conceptualized and implemented, how women independently and collectively construct new leadership role identities, and how leadership identities are retained post training. Themes of nested validation, accepting the belonging narrative, identity emergence, leadership as multiverse, and reflective/reflexive leadership development were discovered. Leadership validation was needed by participants to own their new leadership identity. Through accepting a new narrative, participants confirmed that they belonged in their new leadership role. Identity work occurred on personal and social levels, allowing participants to assume a strengths-based approach to leadership development. Women's only leadership programs, which acknowledge new leadership narratives and identities, allowed emergent leaders an improved opportunity to assume and retain their new role.

Men and women experience unique obstacles on becoming a leader (Ely, Ibarra, \& Kolb, 2011). Distinctive neurological, psychological, and interactive qualities influence how men and women process information, connect with one another, and develop as a leader (Ruderman \& Ohlott, 2005). To promote the development of women leaders, some organizations have created women's only leadership development (WOLD) programs to allow women the opportunity to experience a collaborative and supportive leadership learning environment and learn from a majority position (Debebe, 2011; Ely, et al., 2011). While WOLD program critics suggest that gender specific training fails to provide a real-world leadership forum, other researchers (Ely \& Meyerson, 2000; Gherardi \& Poggio, 2001; Mandell \& Pherwani, 2003) submit that traditional leadership programs, which expect women to develop traditionally male leadership behaviors such as assertiveness and powerfulness, are counterproductive and victimize women for their relational leadership approach. Acknowledged for their collaborative leadership styles (Berry \& Franks, 2010; Boatwright \& Egidio, 2003; Fine, 2009), women who are provided opportunities to connect with other women and who have access to learning strategies which promote selfesteem development are more likely to aspire for leadership opportunities than women who experienced traditional leadership orientations (Boatwright \& Egidio, 2003).
\end{abstract}


The goal of WOLD programs is to advise, challenge, mentor, and affirm emerging women leaders. Characteristically, leader development incorporates a structural process where potential leaders are trained on task oriented knowledge and skills necessary to lead. However, viewing leader training primarily from a leadership project agenda fails to acknowledge the unique leader role identity construction process needed by women to fully develop one's selfconcept as a leader and embrace a leader function (Carroll \& Levy, 2010; Zahidi \& Ibarra, 2010). Considering current organizational, collaborative, and postmodern leadership views as well as valuing the importance of relational connections and social structures, WOLD training must explore the integral process of how social constructs uniquely impact women's leadership identity (Debebe, 2011; Hersted \& Frimann, 2016; Moorosi, 2014).

The purpose of this research is to examine how WOLD training programs not only stimulate the construction of leadership as a core identity in participants, but determine how a new leadership identity would be retained post-training. Despite the expansion in leadership research, a research gap exists between gender only leadership programs and the complexity associated with educational leadership development in women (Coleman \& Fitzgerald, 2008; Fine, 2009). Researchers agree that while the concept of leadership is subjective and difficult to define, leadership development is a relational, complex, and constructive process (Carroll \& Levy, 2010; Ford \& Harding, 2008). While viewing leadership development from a practical, skills-based approach has value, this role structure view fails to fully acknowledge the internal authorship that emerging leaders must develop to embrace their individual leadership role identity (Carroll \& Levy, 2010). We wanted to extend Karp and Helgø's (2008) inquiry "if leadership is dependent on identity, how should one pay attention to identity" (p. 887) within WOLD training programs. Our article contributes to leadership research as it focuses on the unique role interaction impact (Nye, 1976) that leadership training has for emerging women leaders, examines how women independently and collectively construct their identities, and addresses the process, development, and retention of leadership identity for women.

\section{Components of Leadership Identity}

Leadership is "a process of mutual influence that unfolds across time and situations (Marchiondo, Myers, \& Kopelman, 2015, p. 892). The concepts of leadership and leadership identity are multifaceted and dynamic, emerging from lived experiences (Hersted \& Frimann, 2016), and for women, the mental model she has of herself is the basis of her leadership identify. Foundational work regarding leadership identity construction has been proposed by DeRue and Ashford (2010) and studied by others (Debebe \& Reinert, 2014; Ibarra, Snook, \& Guillen Ramo, 2010; Lord \& Hall, 2005; Moorosi, 2014) who have suggested that leadership training is constructed at personal, relational, and collective levels. Karp and Helgø (2008) have extended leadership identity dialogue by contending that leaders negotiate their identity by developing a social construct and then behave within this new role in a way that reinforces this paradigm. This socially constructed leadership identity is therefore dependent on our need for selfrealization and strongly linked to social interactions (Karp \& Helgø, 2008).

Examining leadership role assumption provides an additional forum in which leadership identity construction can be investigated. A process of identity negotiation, cognitive and affective adjustments, and behavioral changes are noted as part of a new leadership role assimilation (Karp \& Helgø, 2008). Leadership education must provide emerging leaders an 
environment for new role conceptualization. The formation, internalization, and retention of a new leadership role considers the role-person merger that occurs when an emerging leader takes on a leader identity. A further examination of the connection between role assumption and leadership identity is examined below.

\section{Theoretical Framework}

\section{Role Assumption}

To contextualize leadership development and the acquisition of a leadership identity for WOLD participants, a theoretical framework of role assumption was examined. In contrast to the traditional notion that an individual's behavior is governed by personal attributes (Smith, Hamond, Ingoldsby, \& Miller, 2009), Ebaugh (1988) contends that behavior is largely governed by "the part one is assigned to play in society" (p. 15). The positions a person occupies within society, termed "roles" (Simon, Stierlin, \& Wynne, 1985), echoes the "parts" that theatrical performers assume for a production (Ebaugh, 1988; Goffman, 1967; Smith, et al., 2009). The individual's roles in work and society comprise the formative contexts that human behavior can be understood (Simon et al., 1985, Smith et al., 2009). When an individual assumes a role, that individual is imbedded within social contexts that exercise powerful influence and external reinforcement on the nature of that role and how it is assumed (Smith et al., 2009). The level of attachment to that newly assumed role is largely determined by the level in which a person adopts, commits to, and fulfills those roles (Ebaugh, 1988; Yodanis, 2003). Recent women's only leadership research (Brue \& Brue, 2016) indicates that emerging women leaders believe that leadership was less of a position to occupy and more of a mindset. This idea is meaningful considering Nye's (1976) perspectives for conceptualizing roles: structural and interaction.

Roles as structure. The Structuralist believes that "phenomena of human life are not intelligible except through their interrelations" (Blackburn, 2005, p. 353) and the relations supplied by a context constitute that structure (Blackburn, 2005). This suggests that any element of a society can only be understood within its societal framework (Smith et al., 2009; Ebaugh, 1998). For Structuralists, social roles have collectively prescribed criterion for actions that are associated with a particular position (Ebaugh, 1998; Yodanis, 2003). Individuals who assume a role in society begin to internalize the behaviors associated with that role (Ebaugh, 1988; Smith et al., 2009). When an individual assumes a new role, the pressure to conform to that role's duties, expectations, and standard of performance are also assumed (Yodanis, 2003). A Structuralists perspective assumes that social pressures and expectations provide a normative regulation of roles; this type of role taking asks persons to internalize the systems of behaviors typically prescribed for that role (Ebaugh, 1988; Nye, 1976). Previous studies (Brue \& Brue, 2016; Ely et al., 2011; Ely \& Meyerson, 2000; Gherardi \& Poggio, 2001) provide insight into the experiences of emerging woman leaders regarding this structural role taking process during and after WOLD program participation.

Role as interaction. For an Interactionist, individuals adopt roles amid interacting with others (Nye, 1976; Yodanis, 2003). Identity then, is found within that individual's social context (Goffman, 1956; 1986); when individuals assume and play out a role within that social context, 
that interaction is a "performance" of that role (Goffman, 1956; 1986). Roles that members of a system (family, workplace, or society) perform become the channel by which these same members are known (Goffman, 1956; 1986). This knowing, either to the self or to others, becomes an identity (Goffman, 1986; Nye, 1976). When considering the interactional nature of role acquisition, Goffman's (1986) person-role formula and role-character formula are particularly germane.

A person-role formula submits that a range of recognized roles are contained in any situation and that there is a limited eligibility for persons able to perform those roles (Diehl \& McFarland, 2010; Goffman, 1986). Historically, the limited eligibility for assuming/performing certain roles existed in the personal frame; these included age, race, and gender (Diehl \& McFarland, 2010). Located in this person-role formula is the notion that an individual's relative involvement in a role will influence the level of identity gained in or from that role (Goffman, 1986). The deeper an individual is involved in a role, the more than individual gains identity from that role (Ebaugh, 1988).

With the role-character formula, the variety of acceptable behaviors in any setting is restricted in meaningful ways (Goffman, 1986). The role-character formula guides who can occupy and stylize roles based on several factors, including (a) the relative status of the individual occupying the role, (b) the status of the role being occupied, and (c) how much a given role's conduct is proscribed (Diehl \& McFarland, 2010). For Goffman (1986), a consistent display of character traits for any particular role, across a variety of social situations, can influence individual and group identity regarding those same roles. The emergence of identities occur "even when the focus of the character frame is primarily maintaining situational order and not differentiating displays of self” (Diehl \& McFarland, 2010, p. 1729).

For Goffman (1967) and Smith et al. (2009), roles are worked out within a social frame of reference. Social interactionists "focus on the way individuals negotiate emergent meanings in order to discover and enact new roles" (Ebaugh, 1988, p. 18). This view of role acquisition suggests that a socially constructed self is internalized while an individual acts out the behaviors agreed upon as formative of that role (Smith et al., 2009). Roles then, are continually produced and reproduced in the interactions with others, a recursive and iterative establishing of role identity formation (Goffman, 1967; Nye, 1976). For Ebaugh (1988), role making is "a constant, ongoing process of thinking, feeling, perceiving, evaluating, and decision making" (p. 17). She further indicates that even though individuals are limited by several conditions controlled by others, roles are largely shaped as individuals assume and interpret those roles (Ebaugh, 1988). Turner's (1978) role-person merger describes the process by which an individual becomes what his or her role requires. The person and role merger goes much deeper than a performance of behaviors required for that specific role, it becomes an identity process (Goffman, 1967; 1986; Yodanis, 2003). The current study attempted to identify the making of roles within the WOLD context.

\section{Research Focus}

\section{Methods}

Delving further into DeRue and Ashford (2010)'s research question of "what are the relational and social processes involved in coming to see oneself, and being seen by others, as a leader" (p. 627), we wanted to focus this research on women's leadership identify construction. While research has focused on overall leadership identity (Carroll \& Levy, 2010; DeRue \& 
Ashford, 2010; Karp \& Helgø, 2008); limited research has explored the social construction of leadership identity in women and the ongoing ways women practice becoming a leader (Day, Fleenor, Atwater, Sturm, \& McKee, 2014). As women are considered more interactive and relationally connected, determining the process by which women socially construct their leadership identity is an area of needed research.

As part of a larger phenomenological research project investigating the perceived experiences of alumni from the state of Oklahoma Career Tech Women in Leadership (OCTWL) program, this extended research element sought to determine the process by which women construct, internalize, and conceptualize their leadership identity. Our initial research project (part 1 - leadership role as structure), sought to clarify what learning elements were most useful in furthering emerging women's leadership roles and career advancements (Brue \& Brue, 2016). A secondary analysis, and the focus on this research, was conducted by examining the data using a new framework (part 2 - leadership role as interaction). Using an alternative lens yielded significant results and was useful in advancing the unique concerns women face within leadership development programs (Moorosi, 2014).

\section{Research Design}

Based on our original research, which emphasized women's-only leadership learning elements and our extended research, which focused of women's relational and social leadership processes, a phenomenological methodology was chosen to investigate how women assimilated and implemented their leadership identity. Providing true data about the investigated phenomena (Rendtorff, 2015), studying a topic void of extensive research (Creswell, 2012), and researching a valuable but assumed aspects of life (Dahl \& Boss, 2005), phenomenology provides an authentic and comprehensive understanding of the social leadership identity construction within aspiring women leaders. As a methodology, phenomenology attempts to gain a deeper awareness by accessing individuals' lived experiences (Byrne, 2001) and describing these experiences using meaningful language (Moustakas, 1994). Capturing the fundamental character of a human experience, phenomenology uses contextually relevant interviews to articulate a common knowledge and meaning of people who have all experienced a particular phenomenon (Kvale \& Brinkman, 2009; Moustakas, 1994).

Leadership programs should engage purposively in follow-up research to determine their operational effectiveness and to assess individual ownership of a recognized leadership identity (Browne-Ferrigno \& Muth, 2012). Using phenomenology to examine WOLD programs offers several benefits including understanding the internalization that leadership training has for emerging women leaders as they develop their leadership identity. Qualitative measures, and specifically phenomenology, can offer worthy insights into participants' experiences through a process of identifying a phenomenon, setting aside previous experiences and habitual views of the topic, collecting data from people who have lived those experiences, distilling data into meaningful units, and rendering an essence of participants' experiences (Creswell, 2012; Moerer-Urdahl \& Creswell, 2004; Moustakas, 1994). With leadership identity as our focus of interest, we initially participated in bracketing (Creswell, 2012) to identify and set aside previous experience with WOLD programs and with social identity construction. Bracketing addresses concerns about confirmability by revealing a researcher's unique viewpoint regarding the study (Schwandt, Lincoln, \& Guba, 2007) and clarifying researcher bias (Creswell, 2012). Neither researcher had an association with the OCTWL program; the first researcher previously 
completed a co-gender leadership program and second researcher has conducted extensive work in role identity construction, but has not focused on leadership development.

\section{Research Setting}

The OCTWL program began in 2010 to create a leadership forum for emerging women leaders. Its goal is to facilitate women leaders by providing leadership knowledge, processing organizational challenges faced by women, and creating a safe space for women to share leadership insights (Oklahoma Department of Career and Technology Education, 2017). Four classes of approximately 20-25 women each, meeting every other month for eight months have completed this program; training curriculum focused on developing leadership acumen, communicating effectively, influencing the organization, and thinking strategically.

\section{Characteristics of Participants}

Purposeful criterion sampling was used to select seven women who completed OCTWL program; two alumni who had completed the class four years previously, and three participants who had completed training two years previously, and two participants who had completed their leadership training six months before our interviews. Research data were verbatim transcripts of in-depth telephone interviews. Focused interviews were conducted lasting approximately 45 minutes each for a total of 295 minutes; interviews consisted of all volunteer participants answering an invariant set of questions, which included: (a) in what way has your leadership identity changed since completing the training; (b) how has your experience in the women's only leadership training program enhanced your progression as a leader; (c) what leadership and identity learning elements do you perceive as most useful to your leadership role; and (d) what elements have helped you within your leadership development. Utilizing Giorgi's (1997) approach to phenomenological research, initial questions were used to obtain descriptions of the experience and follow-up questions were used to elicit meaning. Elucidation questions were asked to deepen interview content and when clarification was needed (Kvale \& Brinkman, 2009).

\section{Data Collection and Analysis}

Upon securing informed consent, interviews were conducted by the lead researcher and digitally recorded using pseudonyms. Post initial data collection, verbatim transcripts were produced and checked for accuracy by researchers and individual participants. Transcripts were analyzed utilizing phenomenological methods (Moustakas, 1994). Using phenomenological reduction (Moerer-Urdahl \& Creswell, 2004; Moustakas, 1994), we independently identified and categorized significant words/phrases made by each participant to create clusters of meaning. With the inclusion of participant quotes, these meaning units were rendered into a detailed description of participants' experience regarding WOLD training (Creswell, 2012; Moustakas, 1994).

Rigorous phenomenology allows for standardization yet adaptability in methodology (Creswell, 2009; Marshall \& Rossman, 2011; Patton, 2002; Trochim \& Donnelly, 2008). The goal was to achieve as comprehensive description as possible of participants lived experiences (Giorgi, 2009). Our seven focused interviews provided us with a rich and thorough description of WOLD experiences. Additionally, several quality assurance mechanisms including member- 
checking, contextualization, detailed descriptions, and bracketing were utilized to create trustworthy and valid results (Lincoln \& Guba, 1985; Maxwell, 2005; Moustakas, 1994).

Member-checking activities (Maxwell, 2005; Schwandt et al., 2007) heightened integrity and accuracy of findings by allowing individual participants to judge the legitimacy of the results. All participants were provided their verbatim interview transcript including (a) our questions and their specific responses, (b) a list of meaningful statements, and (c) our initial joint assessment. Participants recommended no substantive changes. Authentic and detailed descriptions of experiences, accurate language, and meaningful quotes (Berrios \& Lucca, 2006; Moustakas, 1994) addressed dependability concerns by allowing participants to define concepts for themselves (Smith \& Osborn, 2008) and situate the findings within the native context (Finlay, 2011).

\section{Reflection of Key Themes}

Five major themes emerged during our analysis. Reflective statements and meaning units are summarized below.

\section{Theme 1: Nested Validation}

Participants acknowledged the validation sensed from recognizing their own strengths, connecting with other emerging women leaders, and hearing from role models which allowed them to see how leadership was done. Validation of thoughts, feelings, perceptions, behaviors, and decision making processes appeared to be a formative element as participants identified their new role. A three-tiered validation was accomplished in concentric circles, (a) at the mentorship level by connecting with facilitators and leadership champions, (b) at a peer/relational level by networking with other emerging leaders, and (c) at the internal level by accepting a new role identity. This validation allowed participants to develop, test, and adjust their preferred leadership self.

Participant 3 noted, "My leadership experience is pretty much male dominated." She remarked how before this program, she felt inadequate based on how others perceived her and how she perceived her own leadership potential. The validation by mentors became the catalyst driving the process of taking on a new role identity. Participant 1 noted the validation she received from leadership mentors,

There were veterans [leaders] sitting by our side, around the tables with us, just breeding some confidence into us and giving us that "you can do it" attitude. It validated my apprehension and helped me conquer my fears. She [a veteran women leader] patted me on the back and said 'of course you could do it.' That was huge coming from someone of her status. She even said that there was a time when she was a little fearful. She and others spent a lot of time talking about what their leadership philosophies were. They gave us opportunities to hear from different leaders about their different leadership styles.

All participants noted the value of meeting and learning from other leaders who had achieved so much, reducing the perceptions of unsurmountable leadership barriers. 
Participant 1 also noted the value in mutual peer/relational validation, which occurred as part of this leadership training. "I was able to see how other women were able to develop their leadership presence. We reflected back on times that we were wide-eyed and questioning if we could be a leader." Participant 6 described relational validation this way, "it's okay to have feelings, to want to nurture and encourage as a woman." Similarly, other participants noted that connecting with peers allowed them to see the merit of their thoughts and the legitimacy they created for a new leadership role identity. Participate 3 remarked "seeing what all others went though and how they are normal just like me, was absolutely significant; it was a confidence booster."

Regarding the need for self-validation, Participant 5 remarked, "I have always been perceived as being a leader, but I don't know that I owned it, or had not stepped into that role. I didn't recognize it as much as somebody on the outside looking in did." Participant 5 further noted that this training allowed her to hear "the inner transcript that we all have" and address the "self-doubts and uncertainties that my message is not as valid as the next person." Likewise, Participant 1 observed,

I was at a crossroad wondering whether I could move into that leadership role. I was able to overcome my anxiety and conquer my fears regarding my ability to lead. Just listening to other women with similar stories to mine and learning from other established women leaders -- We were all at the same table. We learned together; it changed my perception that 'oh my gosh, they are just people like me- they are not just queens.'

Participant 6 concluded that the WOLD program allowed participants to gain confidence, "confirm things that I needed cemented more," and seek the "opportunities every day to be who we are and still make a difference." Owning and validating a new leadership role identity was formative for participants.

The process and elements used to construct a new leadership identity have been the focus of research. Sparrowe (2005) concluded that individuals formulate their leadership identities based on their own frame of reference of life experiences and from their interpretations of selfnarratives. DeRue and Ashford (2010) proposed that leadership identity development occurs at individual, relational, and collective levels. At a self-concept level, identity is discovered and asserted as part of social interaction while creating new thoughts and beliefs about one's leadership characteristics (DeRue \& Ashford, 2010; Tubin, 2017). Relational leadership identity is constructed among individuals and relationally recognized through the adoption of role identities (DeRue \& Ashford, 2010). While DeRue \& Ashford found this relational level to typically evolve from role identities as leader and follower, we found that peer/relational leadership identities emerged when fellow emerging leaders co-validated each other's leadership identity. Collective leadership identity development results from being a part of a broader social group where the community endorsed a person's leadership identity (DeRue \& Ashford, 2010). For women participating in this leadership development program, having leadership mentors who recognize and authenticate participants' leadership potential was deeply meaningful and critical to their new leadership identity development. All participants, despite the length of time post-training, commented on the significant effect of feeling validated by leadership mentors; this effect was persisting. 


\section{Theme 2: Accepting the Belonging Narrative}

Participants acknowledged that their individual leadership identity aligned with the group's identity, through a co-orienting process of identifying that we belong. Viewing leadership development from not only a resource expansion perspective, participants viewed themselves as belonging. These relational connections were meaningful, justified, and enduring. Participants felt freedom to shared insights, struggles, strategies, and opportunities, building a "common language" (Participant 2 and 3), and witnessing changes in themselves and others. Participant 5 and 7 revealed respectively, "We bonded. It was a real defining opportunity for us to click with women we otherwise would not have" and "I feel I could call anyone of these women, and say, 'Hey I'm facing this today, what would you do? Give me some advice, help me think this through.' They would take time and do it." Participant 2 stated,

We need to know each other and we need to work well together. We need a network of leaders across the organization, to rely upon each other. I think one of the best benefits, I have a new list of people that I can call. Like if I was seasoned in my position and someone was new in their position, she could call and there could be some mentoring there. I have had mentoring opportunities and I can still call on those people. It's bigger than networking - we built a system.

Most program participants acknowledged that they "struggled with their identity" (Participant 4) often comparing themselves to other women and men leaders, which resulted in them feeling that they came "up short without this skill or ability" (Participant 5). The OCTWL program allowed women to accept their stories and co-develop a group leadership narrative, which impacted their leadership development and continual leadership practices. Participant 4 summed it by saying,

We are alike, others have the same struggles as I do. I know if I had a problem, I would have people all across the state doing the exact same thing that I do and they would be able to tell me what they have done in that situation, or what somebody else had done. We have become lifelong resources for each other as we become leaders.

Leadership is a group process (Hogg, 2001) and is "co-authored in social processes of meaning and story construing by using language and communication to interpret lived experiences in the daily stream of ever-changing situations" (Hersted \& Frimann, 2016, p. 149). As women tend to seek relational connections and associations, their desire to connect, belong, and co-orient with other women appears to be foundational to leadership role identity development. Moorosi (2014) concurs by suggesting that emerging leaders who value social support, seek affirmation and acceptance as a leader, and network with other emerging leaders appear to facilitate leadership identity development.

\section{Theme 3: Identity Emergence}

Participants indicated that their leadership identity was developed through "knowing yourself," relating to others, and believing that they could "make a difference" in their new role (Participants 4 and 5); this identity role process was not random, but strategic, taking time and effort to emerge as a leader. Participant 2 stated "I know what gaps there are to fill within my leadership role." Participants also frequently referred to the internal and relational emergence 
process of identifying their uniqueness, owning their strengths, sharing within the group, learning what is important, problem solving issues, and understanding individual/group dynamics. Participant 5 noted two years post WOLD training,

It's learning how to take an outside look at what is needed in that leadership moment and attending to the moment where my leadership might be called for. I had a leadership situation yesterday where I had to put together something spur of the moment. I don't know that I would have been able to do that before the training. I would have doubted that I could have done it. This training gave me the tools to honestly own my strengths and be willing to take risks.

Participant 2 referred to the strategic "mapping out" of her leader role by visualizing and owning a new role. Additionally, Participant 3 discussed her leadership identity process,

That was pretty rough, because you have all of these thoughts that you want to say inside and you have to put words to them. It wasn't that I hadn't formulated my approach; it was intuition type of thing. As women, we have intuition, but we are just not vocal with it. And if we are too vocal, we may get labeled ...then if we are not vocal enough, we get passed over, so I was in that middle ground. I thought that hard work, being there every day, and going above and beyond, would get me the notice. It wouldn't. And so formulating who I wanted to be as a leader, getting the words out of my brain onto a piece of paper and having the work to ready to say whenever I was networking ... that was most helpful.

This leadership role formation process balances the identity formation with perceived leadership views and practice. Sinha and Hanuscin (2017) recognized that leadership students must be exposed to new leadership practices and opportunities, deepen their leadership competence, and connect with leadership role models in order to begin to feel, think, and behave as a leader. Leadership development involves a "fragile process" (Ibarra, Ely, \& Kolb, 2013, p 62) by which emerging leaders view themselves in a new way. Carroll and Levy (2010) contend that the ability to create evolved leadership identities and narratives "becomes a vital dimension of leadership development (and indeed leadership) for both participants and those facilitating their development" (p. 212). This new identity is not about fitting the model, rather it is about embracing opportunities and viewing oneself through a new paradigm.

\section{Theme 4: Leadership as a Multiverse}

The development of leadership identity is not limited to one context but rather is furthered through the attainment of leadership skills and the construction of a new identity narrative. Participants in this study acknowledge the benefit of identifying their true leadership value and learning to lead from their own set of strengths. Participants recounted the process of "defining and refining" leadership philosophies, expanding "ways of knowing things," being emboldened to "develop a personal leadership style," and "laying out in concrete ways how to move forward" (Participant 3). The consensus was that each participant (a) possesses strengths, (b) has the possibility of becoming a leader in title or action, and (c) wrestles with and eventually accepts that "it is okay to be in a leadership role" (Participant 4). The value of the program, per 
participants, was the notion that each woman brought a "different perspective to think about" (Participant 2). Participation allowed them to break some of their own and others' preconceived and restrictive "stereotypes of how a leader should behave" (Participant 4), and training provided them the belief that "I can handle [leadership] better now" (Participant 4).

The capacity to draw out a new unique and authentic leadership style, to take on new responsibilities, to "step into and feel a greater sense of ownership and strength in my new leadership role" (Participant 5) was the appeal of this training. Participant 5 noted,

I know that the role that women play in leadership in any organization is viewed differently than it is for men. And we are often not seen as being strong leaders or just that our style is different. Our training helped us learn to look insightfully into ourselves and draw upon our strengths. We don't always recognize what we have and can bring to the table; we down play it. We are afraid to acknowledge it, we are afraid we will be disregarded or ignored or not acknowledged that what we offer is not as valid as what a man may have. Or even just another woman, because sometimes I think that we compare ourselves with other women as well... and feel our voice isn't as important as what theirs might be. We all have different strengths.

Participants concluded that they learned to recognize what "they could offer to a leadership role was just as important and valuable as someone else" (Participant 5). This realization allowed them to step into a new and true leadership identity, not simply trying to be a leader, but finding the leader within themselves. Hearing others' stories inspired women to "take a bolder stand, and not be afraid to take some risks (Participant 7). Participant 6 summed it by saying,

I think it is a lack of confidence or strength to stand your ground, to identify what it is that you want, and stay on course and achieve that goal. I think that sometimes women in the past have allowed life to slow their progression in leadership roles. But now I see where women are taking care of life first and then going on and doing great things with leadership roles. Holding back has not prepared us or pushed us into leadership roles.

With an intense focus on becoming a leader, some emerging leaders may try to embrace an identity that is not true to themselves. Failing to identify their own strengths, leadership philosophy, and values, some leaders may feel they should adopt a leadership style that is perceived as preferred, traditional, or conventional. (Karp \& Helgø, 2008). Failing to work through the individual process of discovery, identification, and development and believing that one must simply act as a leader typically acts, will leave an emerging leader inadequate to the challenge and can damage the organization and individual alike (Karp \& Helgø, 2008). Authentic and individualized communicative and relational skills are critical for leaders to construct, author, and collaboratively reveal their leadership identity (Hersted \& Frimann, 2016). This process is not static as ongoing leaders must continue to define themselves through continuous interactions (Hersted \& Frimann, 2016).

Effective leader training provides participants with (a) individual knowledge and skills necessary to fulfill a future/potential role (Sirianni \& Frey, 2001; Stead, 2014), (b) interpersonal competence such as emotional and self-awareness and relational competences (Moorosi, 2014), 
and (c) leadership role identity construction (DeRue \& Ashford, 2010). Data collected from our research demonstrated how emerging women leaders personalize and incorporate their new leadership potential into part of their identity. Participants also valued the strength-based approach where they were not forced to learn to "lead as a man" (Participant 5) but constructed an approach allowing them to be "true to ourselves" (Participant 3). This notion of multiple valid ways of being a leader would parallel Hanson's (1995) contention that, "seeing the importance of subjective human group interpretations in contexts and how these constructions enter into behavior means seeing worlds of meaning rather than a single world - $a$ way rather than the way." (p. 85). It is possible, then, to see WOLD participants build and value their way of leading as opposed to what an organization or a society says is the way of leading. Participant 1 cemented this idea, "Everyone leads a little differently but you have to figure out how is the best way you interact with people."

\section{Theme 5: Reflective and Reflexive Leadership Development}

For a new leadership identity to emerge, participants noted the reflective and reflexive processes, which must be addressed. Participants spent time internally discovering and reflecting on who they were. Discovering one's strengths, weaknesses, styles, and approaches constituted a significant portion of leadership curriculum. However, participants also noted a reflexive quality to their leadership development, where through an external process, they viewed themselves as if they were looking in a mirror. This projective process allowed participants to objectively examine their strengths and weaknesses. Participant 2 remarked,

We had an opportunity to look at 'where we are' and 'what is our style.' What is our leadership style? What is our communication style? We had several topics where we examined what our approach was. We looked inward as well. We learned a leadership topic and then applied it to our personal style. There were several "Ah Ha" moments 'wow, my style tends to be this way and I might need to change and do things a little differently.'

Participants acknowledged the value in discovering their strengths and writing their personal leadership philosophy; this leadership refining process was lengthy and allowed participants to merger their new role into their identity. The program helped participants to visualize their leadership goals and view themselves differently.

How emerging leaders view themselves, how others view emerging leaders, and how the emerging leaders feel others view them are fundamental parts of leadership identity construction (Day, et al., 2014; Taylor \& Hood, 2011). Previous research (Alvesson \& Willmott, 2002; Carroll \& Levy, 2010) has approached the intentionality, consciousness, and reflexivity process associated with identity work. Carroll \& Levy (2010) contend that leadership educators must provide subjective and objective-oriented identity work to build a strong leadership identity. All of our participants felt the practice of looking "inwardly," "outwardly," "personally," "realistically," and "impartially" propelled their leadership identity development. Each participant acknowledged how the training helped her overcome constraints, which inhibited their previous ability to view themselves as a leader. Leadership moved beyond the formal title, allowing participants to view leadership as an achievable process and acknowledging that leadership is not a position but a mental approach. Sinha and Hanuscin (2017) found similar 
results noting that leadership education needs to broaden participants' views regarding leadership, expand awareness, and support processes, which forge leadership identities.

\section{Synthesis and Essence of Experiences}

Looking beyond the structural assets gained from the OCTWL program, participants recognized a deeper level of leadership role acquisition. Attendees experienced an overwhelming level of leadership role validation. This validation came from at least three significant sources, the program mentors, fellow participants, and self. Participants appreciated the knowledge confirmation that came from offered curriculum and their leader validation efforts. Recognized women leaders seemed to legitimize the struggle and process of becoming leaders and their presence in the training had a powerfully ratifying effect. Attendees felt a strong group identity with other participants and a "we-ness" seemed to develop. As group identity strengthened, a co-orientation toward acceptance as leaders tended to flourish. For participants, belonging to this group means that you are an emerging leader. With a belonging identity comes acceptance of the struggles and successes of women leaders.

The participants developed an awareness that a leadership role was not so much a title to be gained, but a way of being. They also recognized the developmental nature of becoming what they were aspiring to be. Leadership was now seen as an emergent process that could be mapped-out and lived; participates grew to believe in themselves and in the leadership development process. The changes they began to experience in conjunction with the OCTWL program largely continues to the present time, with some of these changes being predictable, while others were not anticipated. The predicable changes came largely in the form of structural and instrumental knowledge, while the unpredictable changes were about developing selfawareness and confidence as leaders as well as a sense that needed leadership characteristics were already present inside each of them.

An almost universally recognized asset of the OCTWL was that participants were able to see leadership redefined in a non-traditional manner. Bona fide leadership was no longer the exclusive privilege of those modeling male characteristics, but that women, with their unique ways of knowing, can be qualified and effective leaders as well. These emerging leaders came to believe, through self-reflection and internalization, that building a leadership role identity is equifinal, that is, the final state can be reached from divergent beginnings. The building of leadership as an identity was powerfully aided by both reflective and reflexive processes. In the former, participants explored answers of who they are as leaders from within, while in the latter they were able to see themselves in the processes, conversations, and modeling of fellow participants and established leader models. These activities greatly strengthened their rolemaking processes and cemented their identity as leaders.

\section{Application}

Our research objective was to examine how women independently and collectively construct new leadership role identities as part of their leadership education. We suggest WOLD education consider these factors when designing and implementing training programs. 


\section{Self-Efficacy as Part of Leadership Development}

Findings from this research confirm that emerging leaders learned from processing personal interactions, observing modeled behavior, and persisting toward established goals. For participants of a WOLD, these learning elements were nested within the contexts of the group identity of emerging leaders. Bandura (1989) submitted that individuals are motivated by perceived goals as well as realized self-efficacy, personal agency, and self-refection. Beliefs regarding how emerging leaders feel about their ability to succeed and their capacity to develop leadership skills, strengthens leadership development readiness, leadership confidence, and role identification (Lord \& Hall, 2005; Murphy \& Johnson, 2016). Self-efficacy and cognitive motivation play crucial roles in helping an individual achieve goals and reach their desired outcomes (Ponton \& Rhea, 2006) and presented as a critical element in successful leadership development. In addition, this self-efficacy was reinforced in the dialogic exchanges within the collective conscious of the group. Knowing self was then tethered to being known by the group and identifying oneself within that group (Hersted \& Frimann, 2016; Moorosi, 2013).

\section{Feedback and Mutuality}

Leadership role formation as part of the WOLD relies on knowledge and role feedback; receiving follow-up advice and suggestions regarding role-play performance, behavioral modeling efforts, as well as leadership development/striving was regarded as highly influential, helping participants to embrace and solidify a leadership identity. Instrumental and multilevel feedback allowed participants to experience the strengths of multiple perspectives and promote behavioral implementation. Murphy and Johnson (2016) concur by suggesting that the feedback process allows participants to gauge their efforts and results when implementing new leadership behaviors. As women often seek feedback (Ruderman \& Ohlott, 2005), providing follow-up information allowed participants to improve their leader effectiveness, address criticisms, and navigate leadership approaches in a supportive environment. Within WOLD training, each cohort member shared responsibility regarding mutual influence; feedback, casualty, and responsibility were mutually occurring and mutually benefiting mechanisms (Hanson, 1995). In a sense, participants re-authored their perceptions of being leaders by the giving and receiving of relevant feedback (Becvar \& Becvar, 1999).

\section{Leadership Role Identity Development Takes Time}

The OCTWL programs were organized to provide participants with opportunities to develop leadership competencies through action learning and lived experiences, and subsequently apply these competencies back within their respective work places. Participants noted that their mental perception of self was reframed as part of the process, and this process was neither brief nor simple. The collaboration, networking, and coaching process allowed for a deeper understanding of their future leadership role; this process took "meaningful" time. Day et al., (2014) agrees, "it takes time for leaders to progress from a conceptual understanding of their facilitative role to the procedural expression of their leadership competence through specific facilitative behaviors" (p. 66). Based on our research, the establishment and refinement of a leader role identity continued to be a perpetual process; recent graduates and longtime alumni noted this leadership role identity process "easier" but still ongoing. The developmental nature of leader role acquisition points to the value of a continual connection with instrumental and relational training elements. 


\section{Person-Role-Character Identity Formation}

Within the OCTWL training, the formation and adoption of a new leadership role identity was the outcome of knowing self and interacting with others. As participants took on and effectively completed leadership activities (role plays, stretch goals, case studies, etc.), their leadership role and subsequently leadership identity became more formalized; this dynamic echoed Goffman's (1986) person-role formula. Additionally, participation allowed women to believe they possessed the potential or relative status (Diehl \& McFarland, 2010) to occupy a leadership role. With the role-character formula (Goffman, 1986), participants of this study conceptualize, formed, and normed a leadership role identity, which linked their thoughts, feelings, and behavior with their new leadership roles.

\section{Strengths, Weaknesses, Future Research, and Conclusion}

This study contributes to women's only leadership educational research as it focuses on the leadership role interaction that occurs within emerging women leaders, examines how women independently and socially construct their identities, and addresses the long-term impact of leadership identity post-training. The use of phenomenology provides authentic clarification regarding leadership role identity in emerging women leaders. Examining the detailed personal experiences and meaning descriptions (Byrne, 2001; Moustakes, 1994) provides a deeper understanding of the identity formation and role assumption process for WOLD participants. Additionally, the use of multiple frameworks resulted in a comprehensive understanding of how women take on a leadership role.

Our study's limitations focus on the generalizability of data, as this study interviewed women who had experienced one particular WOLD training, and the retrospective approached used in data collection. Experiences of our participants may not be indicative of other WOLD training programs. Additionally, having participants to recall and elicit responses from a previous event many lead to a representational validity of language issue due to recall bias errors within the data (Grant, Curtayne, \& Byrton, 2009; Ledegard \& Gjerde, 2014; Willig, 2008). The use of clarification questions and member-checking procedures were used in hopes to mitigate potential data inaccuracies (Creswell, 2012).

Continued research regarding WOLD programs is recommended. A longitudinal study examining the process of leadership identity adoption, which occurs during and post training would provide leadership education increased knowledge on how to best design training programs. Additionally, expanding leadership methodologies to include other qualitative and quantitative measures could provide a more holistic and exhaustive examination of this process.

"Leaders create their identities as their individual and personal way to leadership" (Karp $\&$ Helgø, 2008, p. 891). This is even more evident with emerging women leaders. The goal of this research was to understand the critical coupling between women identity development and WOLD program participation. While WOLD training must examine leadership development training through a structural development lens (how leadership training be structured, organized, presented, etc.), this type of training must view leadership through an interactive lens to determine how participants have constructed new leadership identities during program participation. Our research revealed a nested validation process was needed to own a new 
leadership identity. Participants accepted a new narrative, which confirmed that they belonged in their new role. Identity work occurred on personal and social levels, allowing participants to assume a strengths-based approach to leadership development. Leadership development training programs, which acknowledge the need to construct a new leadership narratives and ultimately new leadership identities, allowed emergent leaders an improved opportunity to assume and retain their new role.

\section{References}

Alvesson, M., \& Willmott, H. (2002). Producing the appropriate individual: Identity regulation as organizational control. Journal of Management Studies, 39, 619-644.

Becvar, D. S., \& Becvar, R. J. (1999). Systems theory and family therapy: A primer (2nd ed.). New York, NY: University Press of America.

Bandura, A. (1989). Human agency in social cognitive theory. American Psychologist, 44(9), 11751184. doi:10.1037/0003-066X.44.9.1175

Berrios, R., \& Lucca, N. (2006). Qualitative methodology in counseling research: Recent contributions and challenges for a new century. Journal of Counseling and Development, 84, 174-186.

Berry, P., \& Franks, T. J. (2010). Women in the world of corporate business: Looking at the glass ceiling. Contemporary Issues in Education Research, 3(2), 1-9.

Blackburn, S. (2005). Oxford dictionary of philosophy (2nd ed.). Oxford, UK: Oxford University press.

Boatwright, K. J., \& Egidio, R. K. (2003). Psychological predictors of college women's leadership aspirations. Journal of College Student Development, 44(5), 653-669.

Browne-Ferrigno, T., \& Muth, R. (2012). Call for research on candidates in leadership preparation programs. Planning \& Changing, 43(1/2), 10-24.

Brue, K., \& Brue, S. (2016). Experiences and outcomes of a women's leadership development program: A phenomenological investigation. Journal of Leadership Education, 15(3), 75-97. doi:1012806/V15/I3/R2

Byrne, M. M. (2001). Understanding life experiences through a phenomenological approach to research. Association of Operating Room Nurses. AORN Journal, 73(4), 830-832.

Carroll, B., \& Levy, L. (2010). Leadership development as identity construction. Management Communication Quarterly, 24(2), 211-231. doi:10.1177/08933|8909358725

Coleman, M., \& Fitzgerald, T. (2008). Gender and leadership development. In: Lumby, J., Crow, G., and Pashiardis, P. (Eds.) International Handbook on the Preparation and Development of School Leaders. New York, NY: Routledge, pp. 119-155. 
Creswell, J. W. (2009). Research design: Qualitative, quantitative, and mixed methods approaches (3rd ed.). Los Angeles, CA: Sage.

Creswell, J. W. (2012). Qualitative inquiry \& research: Choosing among five approaches (3rd ed.). Los Angeles, CA: Sage.

Dahl, C. M., \& Boss, P. (2005). The use of phenomenology for family therapy research: The search for meaning. In D. H. Sprenkle, \& F. P. Piercy (Eds.). Research methods in family therapy (3rd ed., pp. 63-84). New York, NY: Guilford.

Day, D. V., Fleenor, J. W., Atwater, L. E., Sturm, R. E., \& McKee, R. A. (2014). Advances in leader and leadership development: A review of 25 years of research and theory. Leadership Quarterly, 25(1), 63-82. doi:10.1016/j.leaqua.2013.11.004

Debebe, G. (2011). Creating a safe environment for women's leadership transformation. Journal of Managerial Education, 35(5), 679-712. doi:10.1177/1052562910397501

Debebe, G., \& Reinert, K. A., (2014). Leading with our whole selves: A multiple identity approach to leadership development. In: Miville M., \& Ferguson A. (Eds.) Handbook of Race-Ethnicity and Gender in Psychology. (pp. 271-293). New York, NY: Springer.

DeRue, D. S., \& Ashford, S. J. (2010). Who will lead and who will follow? A social process of leadership identity construction in organizations. Academy of Management Review, 35(4), 627647.

Diehl, D., \& McFarland, D. (2010). Toward a historic sociology of social situations. American Journal of Sociology, 115, 1713-1752. Retrieved from https://ed.stanford.edu/sites/default/files/mcfarland/Diehl_McFarland2010.pdf

Ebaugh, H. R. F. (1988). Becoming an ex: The process of role exit. Chicago, IL: The University of Chicago Press.

Ely, R. J., Ibarra, H., \& Kolb, D. M. (2011). Taking gender into account: Theory and design for women's leadership programs. Academy of Management Learning \& Education, 10(3), 474-493. doi:10.5465/amle.2010.0046

Ely, R. J., \& Meyerson, D. E. (2000). Theories of gender in organization: A new approach to organizational analysis and change. Research in Organizational Behavior, 22, 103-151. doi:10.1016/S0191-3085(00)22004-2

Fine, M. G. (2009). Women leaders' discursive constructions of leadership. Women's Studies in Communication, 32(2), 180-202. doi:10.1080/07491409.2009.10162386

Finlay, L. (2011). Phenomenology for therapists: Researching the lived world. Chichester, West Sussex: John Wiley \& Sons, Ltd. 
Ford, J., \& Harding, N. (2008). Move over management: We are all leaders now. Management Learning, 38,475-493.

Gherardi, S., \& Poggio, B. (2001). Creating and recreating gender order in organizations. Journal of World Business, 36(3), 245-259. doi:10.1016/S1090-9516(01)00054-2

Giorgi, A. (2009). The descriptive phenomenological method in psychology: A modified Husserlian approach. Pittsburgh, PA: Duquesne University Press.

Giorgi, A. (1997). The theory, practice, and evaluation of phenomenological method as a qualitative research practice procedure. Journal of Phenomenological Psychology, 28(2), 235-260.

Goffman, E. (1956). The presentation of the self in everyday life. New York, NY: Doubleday.

Goffman, E. (1967). Interaction ritual: Essays in face-to-face behavior. New Brunswick, NJ: Aldine Transaction.

Goffman, E. (1986). Frame Analysis: An essay on the organization of experience. Boston, MA: Northeastern University Press.

Grant, A. D., Curtayne, L., \& Byrton, G. (2009). Executive coaching enhances goal attainment, resilience, and workplace well-being: A randomized controlled study. Journal of Positive Psychology, 4(5), 396-407. doi:10.1080/17439760902992456

Grant, A. D., \& Taylor, A. (2014). Communication essentials for female executives to develop leadership presence: Getting beyond the barriers of understating accomplishment. Business Horizons, 57(1), 73-83. doi:10.1016/j.bushor.2013.09.003

Hanson, B. G. (1995). General systems theory: Beginning with wholes. Toronto, Canada: Taylor \& Francis.

Hersted, L., \& Frimann, S. (2016). Constructing leadership identities through stories. Journal for Critical Organization Inquiry, 14(4), 149-162.

Hogg, M. A. (2001). Social categorization, depersonalization, and group behavior. In M. A. Hogg \& R. S. Tindale (Eds.), Blackwell Handbook of Social Psychology: Group Processes (pp. 56-84). Oxford, English: Blackwell.

Ibarra, H., Ely, R. \& Kolb, D. (2013). Women rising: The unseen barriers. Harvard Business Review, 91(9), 61-66.

Ibarra, H., Snook, S., \& Guillén Ramo, L. (2010). Identity-based leader development. In N. Nohria \& R. Khuruma (Eds.) Handbook of Leadership Theory and Practice (pp. 657-678). Boston, MA: Harvard Business School Press. 
Karp, T. \& Helgø, T. (2009). Leadership as identity construction: The act of leading people in organizations: A perspective from the complexity sciences. Journal of Management Development, 28(10), 880-896. doi:10.1108/02621710911000659.

Kvale, S., \& Brinkman, S. (2009). Interviews: Learning the craft of qualitative research interviewing (2nd ed.). Thousand Oaks, CA: Sage.

Ladegard, G., \& Gjerde, S. (2014). Leadership coaching, leader role-efficacy, and trust in subordinates. A mixed methods study assessing leadership coaching as a leadership development tool. The Leadership Quarterly, 25, 632-646.

Lincoln, Y. S., \& Guba, E. G. (1985). Naturalistic inquiry. Beverly Hills, CA: Sage.

Lord, R. G., \& Hall, R. J. (2005). Identity, deep structure and the development of leadership skill. Leadership Quarterly, 16(4), 591-615. doi:10.1016/j.leaqua.2005.06.003

Mandell, B., \& Pherwani, S. (2003). Relationships between emotional intelligence and transformational leadership: A gender comparison. Journal of Business and Psychology. 17(3), 387-404. doi:10.1023/A:1022816409059

Marchiondo, L. A., Myers, C. G., \& Kopelman, S. (2015). The relational nature of leadership identity construction: How and when it influences perceived leadership and decision-making. The Leadership Quarterly, 25(5), 892-908.

Marshall, C., \& Rossman, G. B. (2011). Designing qualitative research (5th ed.). Los Angeles, CA: Sage.

Maxwell, J. A. (2005). Qualitative research design: An interpretive approach (2nd ed.). Thousand Oaks, CA: Sage.

Moerer-Urdahl, T., \& Creswell, J. W. (2004). Using transcendental phenomenology to explore the "ripple effect" in a leadership mentoring program. International Journal of Qualitative Methods, 3(2), 19-35. Retrieved from http://ejournals.library.ualberta.ca/index.php/IJQM/article/view/4470/3594

Moorosi, P. (2014). Constructing a leader's identity through a leadership development programme: An intersectional analysis. Educational Management Administration \& Leadership, 42(6), 792-807. doi: $10.1177 / 1741143213494888$

Moustakas, C. (1994). Phenomenological research methods. Thousand Oaks, CA: Sage.

Murphy. S. E., \& Johnson, S. (2016). Leadership and leader developmental self-efficacy: Their role in enhancing leader development efforts. New Directions for Student Leadership, 2016(149). 73-84. doi:10.1002/yd.20163.

Nye, F. I. (1976). Role structure and analysis of the family. Beverly Hills, CA: Sage. 
Oklahoma Department of Career and Technology Education (2017). CareerTech Women in Leadership. https://www.okcareertech.org/

Patton, M. Q. (2002). Qualitative research and evaluation methods (3rd ed.). Thousand Oaks, CA: Sage.

Ponton, M. K., \& Rhea, N. E. (2006). Autonomous learning from a social cognitive perspective. New Horizons in Adult Education \& Human Resource Development, 20(2), 38-49.

Rendtorff, J. D. (2015). Case studies, ethics, philosophy, and liberal learning for management profession. Journal of Management Education, 39(1), 36-55. doi:10.1177/1052562914562282

Ruderman, M. N., \& Ohlott, P. J. (2005). Leading roles: What coaches of women need to know. Leadership in Action, 25(3), 3-9.

Schwandt, T. A., Lincoln, Y. S., \& Guba, E. G. (2007). Judging interpretations: But is it rigorous? Trustworthiness and authenticity in naturalistic evaluation. New Directions for Program Evaluation, 114, 11-25. doi:10.1002/ev.223

Simon, F. B., Stierlin, H., \& Wynne, L. C. (1985). The language of family therapy: A systemic vocabulary and sourcebook. New York, NY: Family Process Press.

Sinha, S., \& Hanuscin, D. L. (2017). Development of teacher leadership: A multiple case study. Teaching and Teacher Education, 63, 356-371. doi:10.1016/j.tate.2017.01.004

Sirianni, P. M., \& Frey, B. A. (2001). Changing a culture: Evaluation of a leadership development program at Mellon Financial Services. International Journal of Training \& Development, 5(4), 290-301. doi:10.111/1468-2419.00141

Smith, J. A., \& Osborn, M. (2008). Interpretative phenomenological analysis. In J. A. Smith (Ed.), Qualitative psychology: A practical guide to research methods (2nd ed., pp. 53-80). London, England: Sage.

Smith, S. R., Hamon, R. R., Ingoldsby, B. B., \& Miller, J., E. (2009). Exploring family theories (2nd ed.). New York, NY: Oxford University Press.

Sparrowe, R. T. (2005). Authentic leadership and the narrative self. Leadership Quarterly, 16(3), 419439. doi:10.1016/j.leaqua.2005.03.004

Stead, V. (2014). The gendered power relations of action learning: A critical analysis of women's reflections on a leadership development programme. Human Resource Development International, 17(4), 416-437. doi:10.1080/13678868.2014.928137

Taylor, S. N., \& Hood, J. N. (2011). It may not be what you think: Gender differences in predicting emotional and social competence. Human Relations, 64(5), 627-652.

doi:10.1177/0018726710387950 
Trochim, W. M. K., \& Donnelly, J. P. (2008). The research methods knowledge base (3rd ed.). Mason, $\mathrm{OH}$ : Cengage Learning.

Tubin, D. (2017). Leadership identity construction practices. Educational Management Administration \& Leadership, 45(5), 790-805. doi:10.1177/1741143216682503

Turner, R. H. (1978). The role and the person. American Journal of Sociology, 84(1), 2-23. doi:10.1086/226738

Willig, C. (2008). Introducing qualitative research in psychology: Adventures in theory and method (2nd ed.). New York, NY: McGraw-Hill.

Yodonis, C. L. (2003). Role theory. International Encyclopedia of Marriage and Family. Retrieved from http://www.encyclopedia.com/topic/Role_Theory.aspx\#1

Zahidi, S., \& Ibarra, H. (2010). The corporate gender gap report 2010. World Economic Forum. Geneva, Switzerland.

\section{Author Biographies}

Dr. Krystal Brue is an Assistant Professor in Business at Cameron University within the School of Graduate and Professional Studies. She holds dual HR certifications as a Senior Human Resource Professional and as a SHRM Senior Certified Professional. Her research areas of interest include leadership, work-life balance, change management, human resource management, and employee engagement. Email: kbrue@cameron.edu

Shawn Brue holds a Ph.D. in Marriage and Family Therapy. He has been a Licensed Professional Counselor and Licensed Marriage and Family Therapist for over 25 years as well as a clinical supervisor for over 17 years. He serves as a therapist at the Christian Family Counseling Center and adjunct faculty at Northcentral University and Cameron University. Email: shawnbrue@yahoo.com 